\title{
Policy options in a worst case climate change world
}

\author{
Rob Swart • Natasha Marinova
}

Received: 15 December 2009/Accepted: 17 May 2010 /

Published online: 3 June 2010

(C) The Author(s) 2010. This article is published with open access at Springerlink.com

\begin{abstract}
Climatic changes more rapid and extreme than assessed by the IPCC cannot be excluded, because of the possibility of positive earth system feedbacks and thresholds. Do today's policy makers have to take these into account, and if so, are the options different from those considered today? The paper briefly summarizes the types of extreme climatic changes noted in the literature and then evaluates the options to address them in a what-if manner. Different from other studies, which usually look at only one type of measure, we consider a broader portfolio of options: drastic emissions reduction programmes, drawing greenhouse gases from the atmosphere ("carbon dioxide removal"), "emergency cooling" through influencing the radiative balance of the atmosphere ("solar radiation management"), and finally adaptation beyond the options considered seriously today. Politics will have to decide on the choice or mix of "emergency" measures, but research can ensure that such decisions are based on the best scientific information. If through concerted international efforts to mitigate greenhouse emissions low stabilization levels could be reached, such decisions may never have to be made. However, research in support of some form of a "plan B" is now warranted, focusing on those options that have the most positive ratio between potential effectiveness and feasibility on the one hand, and environmental and political risks on the other hand. Such plan should not be limited to one set of options such as geo-engineering and should explicitly take into account not only the relationships between the options but also the wide variety in characteristics of the individual options in terms of effectiveness, feasibility, environmental risks, and political implications.
\end{abstract}

Keywords Climate policy - Geoengineering - Governance $\cdot$ Extreme climate change Mitigation

R. Swart $(\square) \cdot$ N. Marinova

Alterra, Wageningen University and Research Centre, Droevendaalsesteeg 4, Wageningen, The Netherlands e-mail: rob.swart@wur.nl

N. Marinova

e-mail: natasha.marinova@wur.nl 


\section{A basis for emergency climate policies?}

Since the publication of the IPCC's 4th Assessment Report in 2007 (AR4), various developments have given rise to suggestions that more drastic measures may be required to respond to climate change than considered until recently, including controversial options such as coercive changes in consumption and production practices, or geoengineering. IPCC Third Assessment Report (TAR) and AR4 paid relatively little attention to geoengineering. IPCC included geoengineering explicitly in its terms of reference for the next assessment report, but in the AR4 only a rather cursory discussion (one page on ocean fertilization and "technologically-varied solar radiative forcing" in the more than 800 pages Working Group III report) was included (IPCC 2007a). In the years following the AR4 the number of associated publications increased rapidly and particularly geoengineering is very rapidly entering the mainstream political and scientific debate, during which process early suggestions for a new "Manhattan Project" to save the earth (e.g., Michaelson 1998) are being replaced by a more differentiated debate (e.g., Yang and Oppenheimer 2007; Schneider 2008; Royal Society 2009). Three reasons for this can be identified:

- Increasing recognition of uncertain earth system feedbacks and thresholds suggest that climate changes more rapid and extreme than assessed by the IPCC are in the realm of possibilities (Richardson et al. 2009; Füssel 2009; Steffen 2009; UNEP 2009).

- Ecological and societal systems may be more vulnerable than assessed before (e.g., Smith et al. 2009).

- Efforts to achieve global reductions of greenhouse gas emissions may be insufficient to stabilize greenhouse gas concentrations and prevent major impacts (Rogeij et al. 2010); e.g., the Royal Society's (2009) geoengeering assessment takes this as the point of departure. The failure of the climate change summit in Copenhagen in 2009 to reach an agreement on a global reduction target and on the timing for peaking global emissions further postpones a global post-2012 agreement. Therefore it can be expected that this argument will play an even more important role in the future.

A number of recent assessments of potential "tipping points" have raised concerns about a possible acceleration of climate change (CCSP 2008; Kriegler et al. 2009; Lenton et al. 2008). These tipping points are generally characterized by a lack of knowledge on the physical mechanisms involved as well as a lack of observational data, seriously limiting the possibilities of providing probabilistic statements to policymakers, although attempts to overcome this barrier are starting. Kattenberg and Verver (2009), for example, provide a subjective, qualitative judgment of the likelihood and scope of impacts of a number of feedbacks and other "eventualities" (Fig. 1). Schneider (2008) noted that IPCC (2007b) estimated that it is likely (66-90\% probability assessed by the authors) that global mean temperature in the highest (A1FI) scenario would be between $2.5^{\circ} \mathrm{C}$ and $6.4^{\circ} \mathrm{C}$ by 2100 , or would have a chance of $5-17 \%$ that it would be above $6.4^{\circ} \mathrm{C}$. Schneider also noted that the number and intensity of abrupt events and the possibility of irreversible damages increases non-linearly with warming, and that a $5-17 \%$ chance is well above the threshold above which people usually take out insurance.

The sensitivity and adaptive capacity of natural and social systems is also poorly known, and the future of socio-economic developments and the level of success of attempts to limit greenhouse gas emissions cannot be predicted. Therefore, in this paper we do not make any 


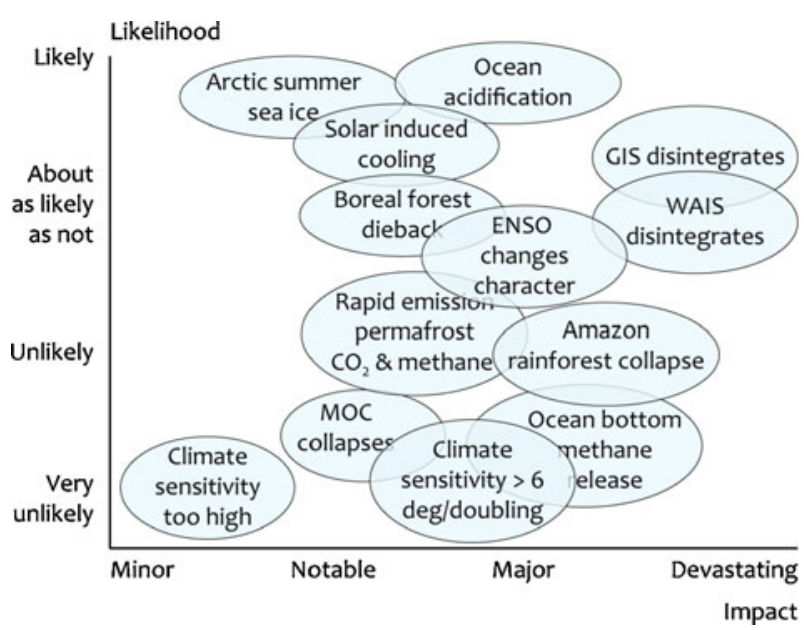

Fig. 1 Thirteen "climate eventualities", the scope of their potential impacts, and expert judgment about their likelihood of occurrence (Kattenberg and Verver 2009). MOC $=$ Meridional Overturning Circulation, WAIS $=$ West Antarctic Ice Sheet, GIS $=$ Greenland Ice Sheet, ENSO $=$ El Nino Southern Oscillation

additional attempt to determine the likelihood of the above three claims, but just acknowledge that acceleration of climate change cannot be excluded and the consequences would be grave. This alone justifies the exploration of possible response options that could be implemented as a kind of "plan B" in case the options currently being envisaged to mitigate climate change would turn out to be insufficient or infeasible. In the rest of this paper we evaluate the pros and cons of such more far-reaching options to address extreme climatic changes in a "what-if" manner.

\section{A variety of emergency response options}

Different from other studies, which often look at only one type of option, we consider a broad portfolio of emergency climate response options (Swart et al. 2009):

1. Drastic emissions reductions: A national and international "crash" emissions reduction programme, including innovative technologies, systems transitions, and structural and behavioural changes;

2. Carbon dioxide removal: Options drawing greenhouse gases from the atmosphere, including land-use and forestry, enhanced ocean sequestration, algae, artificial air capture, mineral sequestration;

3. Solar radiation management (SRM): "Emergency cooling" through influencing the radiative balance of the atmosphere, such as stratospheric aerosol injection, space reflectors, cloud modification, terrestrial albedo modification; and

4. Emergency adaptation. Adaptation options beyond those considered seriously today, including far-reaching options for water safety, fresh water supply, nature protection, climate-proofing of urban areas and infrastructure networks, migration from vulnerable areas, and integration of extreme climate change into non-climate policy. 
Other studies have looked at subsets of these categories, particularly geo-engineering (e.g. Schneider 2008; Boyd 2008; Royal Society 2009). ${ }^{1}$

The current order of preferences for the four types of options of many experts and policy makers appears to be as above: impacts are to be avoided as much as possible, and the primary way to achieve this is through emissions reductions, while enhancing sinks can also play a complementary role, provided that negative consequences for biodiversity and local livelihoods are avoided. Solar radiation management is not yet considered as a serious option largely because of the unknown risks. Organizing a coordinated orderly process to cope with disastrous climate impacts is also not yet seriously considered in mainstream discussions about climate change response. But do such preferences hold in a situation of accelerating climate change? We use four sets of criteria to address this question:

- Effectiveness: the effect on radiative forcing, system response time, time needed for full deployment,

- Feasibility: technological (idea, demonstration/prototype, established), economic, and social (requiring behavioural change, controversial),

- Environmental risks: other climate effects, non-climate environmental effects such as air pollution, ecosystem risks,

- Political implications: ethical questions, governance and security issues.

While, initially, we planned to use quantitative information to support our evaluation along these criteria as much as possible, we found that available numbers on effectiveness, risks or costs are not only scarce, but also incomplete, very speculative, and arguably biased by the perspective of the authors. An evaluation on the basis of qualitative considerations is therefore more appropriate at this stage of knowledge development. Only as a more substantial body of peer-reviewed literature becomes available, quantitative comparison may become meaningful. We will only provide some numbers as examples. In the next section, the four categories of options will be summarized and concisely evaluated against these four criteria.

\section{Drastic emissions reductions}

Stepping up current mitigation policies is a priority response option, particularly reducing greenhouse gas emissions. According to the IPCC (2007a), for all economic sectors a wide variety of options is available at modest costs that can be applied to stabilize atmospheric concentrations of greenhouse gases. IPCC (2007a) suggests that "in 2030 macro-economic costs for multi-gas mitigation, consistent with emissions trajectories towards stabilization between $445 \mathrm{ppm}$ and $710 \mathrm{ppm} \mathrm{CO}_{2}$-eq, are estimated at between a 3\% decrease of global GDP and a small increase, compared to the baseline". A very important factor in evaluating the possibilities to stabilize greenhouse gas concentrations as quickly as possible is the maximum rate of emissions reductions that can be achieved. According to WBGU's carbon budget approach (WBGU 2009), if global emissions would peak by 2011, global emissions would have to decline by $3.7 \%$ per year to have a two thirds chance to stay within the EU's long-term temperature goal of $2^{\circ} \mathrm{C}$ increase as compared to pre-industrial levels. For peaking of global emissions in 2015 and 2020, rates of 5.3\% and 9\% would be required, respectively.

\footnotetext{
${ }^{1}$ While all solar radiation management options are usually included in the term geo-engineering, this does not apply to all carbon dioxide removal options. For example, (re-) afforestation and aquatic carbon capture through algal systems are sometimes included and sometimes not. Therefore, in this paper we minimize the use of the term geoengineering but mainly use the terms solar radiation management and carbon dioxide removal.
} 
During the Copenhagen climate summit in 2009, 2020 was discussed as the year for global emissions peaking that may combine desirability with feasibility. While about 10 years ago, the maximum feasible rate of change was estimated to be from $2-4 \%$ per year (assuming no premature replacement of capital), currently it is estimated that higher rates are possible, especially in an emergency situation (van Vuuren and Stehfest 2009). There are two reasons for this: 10 years ago the combination of biofuels and carbon capture and storage (BECS) did not yet feature in the menu of options, and in an emergency situation also measures in the area of behavioural and structural economic changes can come within reach. Examples of unconventional measures that could increase the rate of emissions reductions include

- Scaling up of current policy. The first step could be to push current policy to the extremes. McKinsey (2009) gives a recent overview of technological options in line with stabilization of greenhouse gas concentrations at $2^{\circ} \mathrm{C}$. A Green New Deal would combine policies to solve the "triple crunch" of the credit crisis, climate change and high oil prices, re-regulating finance and taxation (Green New Deal Group 2008). In Europe feed-in support and preferential access to renewable energy could be increased, the European Union Emission Trading System (EU ETS) caps tightened, and all energy standards strictly enforced. Globally, similar measures could be pursued. Views on technologies which are currently controversial in many countries like carbon capture and storage and nuclear energy may change. A study of Pidgeon et al. (2008) conducted in UK demonstrated, for instance, that while the share of people with preference to nuclear power as a means to combat global change was only $14 \%, 48 \%$ of the respondents agreed or strongly agreed that "nuclear energy will make a substantial future contribution to reliable and secure supplies of electricity", i.e., only a framing of a problem already leads to very different popular views on the acceptability of technologies.

- Government coordination of energy and industry. On the supply side of the economy, governments could reverse privatisation and resort to coordination and control over energy and industry infrastructure and operation, just as governments increased control over the banking sector during the recent financial crisis. Although this option is at odds with the still dominant perspectives of free personal choice and markets, the example of California, where utilities can control the temperature of new homes and commercial buildings in emergency situations such as heat waves, is an interesting example (California Energy Commission 2008).

- Government interference with energy demand. Some policy measures are effective, but rather controversial as they limit freedom and consumer choice, and interfere with individuals' privacy. Examples are personal travel and transport budgets, obliging households and industry to use certain appliances (or discard others), limiting hot water use and space heating or cooling, and imposing dietary restrictions. Tradeable Emissions Quota (TEQs; Fleming 2007a) and Personal Carbon Allowances (PCAs, Hillman and Fawcett 2004) are two examples of demand control mechanisms.

- Overarching cross-sectoral coordination. The national and international climate policies have been developed in a piecemeal sector-by-sector approach focusing on improvements of individual technologies. This prevents a serious discussion on transitions at a systems level, not limited by national boundaries (e.g. mobility rather than car efficiency, food security rather than crop yields). Especially the reduction of mobility needs of persons and merchandise by intelligent transport infrastructures and urban planning in each region, combined with a growing price signal can offer effective emissions limitations (EpE/Iddri 2008). 
Although some of the drastic emissions reduction options may arguably be amongst the least controversial and most sustainable of the four categories of options, the effectiveness of drastic emissions reductions to rapidly counteract the consequences of accelerating climate change is limited. Not only do they require major and time-consuming technological and social transitions, also the inertia of the climate system contributes to a delayed effect. From a technological perspective, their feasibility is large, because most of the options are well-known today. However, major economic and political hurdles will have to be taken because many of the options are very controversial, affecting personal choice or having real or perceived risks. The environmental risks of these options are generally relatively limited - with exceptions, such as nuclear energy. Many of the options, however, have co-benefits. The political challenges are large, illustrated by the difficulties to reach agreement about the current emissions reductions proposals, which are lower than those required for effective emergency response.

\section{Carbon dioxide removal}

Even if drastic emissions reductions measures are theoretically possible, the challenges to achieve the required rates of change are enormous and it may become necessary to invest in additional options, like removing carbon from the atmosphere. A series of options for carbon removal have been proposed so far, some of which are currently already on the research and policy agenda, such as for instance (re-)afforestation, while others, such as artificial methods, are in earlier stages of development. The "mainstream" groups of options are listed below, although we are aware that they might not capture all possible options. Richard Branson's Earth Challenge 25M\$ prize for the best idea to remove carbon from the atmosphere has already led to more than 800 submissions at the time of writing of this paper, for instance.

- (Re-)afforestation. Forestry projects already feature prominently in today's mitigation menu, but their upscaling would be required in order to become an effective emergency response measure (e.g., Nabuurs et al. 2007; van Minnen et al. 2008). Foresting the desert, supported by irrigation with desalinated sea water has been recently proposed as a large-scale measure (Ornstein et al. 2009). Ornstein et al. (2009) suggest that their plan represents a mature technology option, whose annual sequestration potential would equal the amounts of $\mathrm{CO}_{2}$ (carbon dioxide) emitted into the atmosphere from burning fossil fuels. The irrigation costs could be covered by adding about $0.26 \$$ per liter to pump prices.

- Aquatic carbon sequestration (algae). $\mathrm{CO}_{2}$ and other greenhouse gases (GHGs) can also be drawn from the atmosphere through sequestration by algae in open aquatic systems or, more effectively, bio-reactors (e.g., Sijtsma and Reith 2006; NASA 2009). The harvested algae can be used for the production of bio-energy, replacing other (fossil) fuels. None of the current pilot projects for biofuel production is at a commercial scale yet, and the upscaling of bio-reactors still remains a big challenge (Janssen et al. 2003). A large scale mass production is required, however, if cultivated algae is to make a dent in the global $\mathrm{CO}_{2}$ concentration. Grobelaar et al. (2000) calculated, for example, that for the fixation of $50 \%$ of $\mathrm{CO}_{2}$, emitted from a $300 \mathrm{MW}$ coal-fired power plant approximately $100 \mathrm{~km}^{2}$ of algal culture may be needed.

- Enhanced ocean sequestration. This option mostly refers to the enhancement of the 'biological pump' which draws down carbon sequestered in biomass from the top to 
deeper layers of the oceans, or to the 'solubility pump', transferring and redistributing inorganic carbon into the ocean (e. g., Lampitt et al. 2008). The most studied option is adding macronutrients, such as nitrogen or phosphorus, or micronutrients, such as iron nutrients, to stimulate primary productivity. Tests with iron fertilization have been implemented, but the potential to influence $\mathrm{CO}_{2}$ concentrations effectively for a long time remains very uncertain. Rau et al. (2007) has revived the exploration of a separate chemical option to increase alkalinity of the ocean and subsequent carbon uptake through liming of the ocean, coined first by Kheshgi (1995). As the application of this option might have unknown environmental side-effects, its commercial deployment is currently banned by the London Convention.

- Biochar. Biochar is a black carbon, produced by pyrolysis of biomass, allowing for carbon sequestration and long-term storage (Lehmann et al. 2006). It can be produced from wood or from waste, which otherwise would release carbon dioxide (Lehmann 2007). Biochar might have additional positive environmental and economical effects, because it can be used as soil additive to improve soil quality and fertility. Another advantage is that it can be a by-product from energy production; the co-production of biochar and energy involves a conflict of maximising them simultaneously, however, e.g., $45 \%$ yield of biochar would bring down the recoverable energy from the biomass to a maximum of $32 \%$, while for a $20 \%$ yield of biochar the recoverable energy from the biomass would be $72 \%$ (Woolf 2008).

- Air capture. Proposed artificial air capture systems remove $\mathrm{CO}_{2}$ from the air and deliver a pure $\mathrm{CO}_{2}$ stream for sequestration and disposal (e. g., Lackner et al. 2001; Keith et al. 2005; Nikulshina et al. 2007). All schemes use some 'sorbent' material, which reacts with $\mathrm{CO}_{2}$ and binds it. After that, $\mathrm{CO}_{2}$ is removed from the sorbent by using, for instance, a chemical reaction, heating or vacuum. All proposed technologies require much energy. The design of Lackner, for instance, claimed by the authors to have the best energy performance, uses about $1.1 \mathrm{MJ}$ for each kilogram of $\mathrm{CO}_{2}$ captured. For one energy intensive economy like the Chinese, $\mathrm{CO}_{2}$ captured with such a device would be approximately four times more than $\mathrm{CO}_{2}$, released during the operation of the device, but further developments, e.g., improvements in the design and the chemistry of the sorbent, are expected to decrease the energy requirements (Lackner 2009).

- Enhanced weathering. Through industrial mineral carbonation the natural weathering of minerals can be accelerated considerably. When followed by spreading out powdered minerals such as olivine over larges surface areas, it would lead to carbon fixation (Stephens and Keith 2008). Since mineral carbonation is a slow process, pretreatment such as crushing, elevated temperatures and pressure can be applied to accelerate the reactions. The trade-offs between costs, energy requirements and the rate of reactions are significant, however, and have not been resolved yet.

Similar to drastic emissions reductions, the effectiveness of carbon dioxide removal as an emergency option is limited by delays in the climate system and the time needed to apply the option at a scale large enough to make a global difference. The effectiveness of the sequestration by algae and enhanced mineral weathering can be increased, if these processes are combined with carbon capture of flue gases. The effectiveness of sustainable carbon uptake by ocean fertilization has not been confirmed by the tests yet. Enhanced mineral weathering and air capture require additional energy, and may only make sense if renewable energy is used - but then why not use this renewable energy directly to satisfy human needs? The feasibility of these options varies: while options like forestation and biochar are implemented already now, other methods still have a long way to go from the 
small scale testing phase or drawing board to actual implementation. Environmental risks also vary between the options. Because of the unknown risks, an international moratorium on ocean fertilization has been agreed until 'scientists better understand the potential risks and benefits of manipulating the oceanic food chain'. Also, mainly in the US much efforts currently attempt to produce genetically modified algae strains in order to overcome some of the current production barriers. However, algae, being among the most adaptable organisms on earth and at the basis of the food web, could have substantial environmental risks, if their genetically modified strains are released or escape into nature (Austin 2009). As to political implications, options that require much space raise sovereignty questions, while options with serious risks require international consent and coordination.

\section{Solar radiation management}

The third category of options aims at influencing the radiative balance of the earth. Various ideas have been proposed:

- Injections of aerosols or aerosol precursors into the stratosphere. This option was coined almost 30 years ago by Budyko (1969) but gained much attention recently when Nobel Prize winner Crutzen revived the debate (Crutzen 2006). Evidence of cooling after large volcanic eruptions implies that this option can be effective to abate global warming (Wilson et al. 1993). It is suggested that because of the relatively long residence time (approximately 2 years), injection into the stratosphere would be most appropriate. The aerosols, or their precursors, could be carried to the stratosphere on balloons, rockets and airplanes, or by artillery guns (NAS 1992). Modeling studies warn, however, about the changing spatial climate patterns, like warming at high latitudes (Matthews and Caldeira 2007) and reduction in intensity of the hydrological cycle of about $5 \%$ (Bala et al. 2008), would this option be implemented.

- Reflectors in space. Radiative forcing can be influenced by launching space-based 'sunshade' shields, situated at the Lagrange point between the Earth and the sun at a distance of about 1.5 million kilometres from our planet (Early 1989; Seifritz 1989). They could be either large (e.g., a single 2,000 km diameter shield of thin aluminium foil) or small reflectors (e.g., a cloud of many transparent metresized spacecraft, Angel 2006). While the aerosol option, described above, would require frequent renewal, the space reflectors would have a longer lifetime. At the same time, theoretically, they could be removed or turned off immediately if undesirable effects would occur. This apparent benefit is also a large risk, because the system would be very vulnerable to intentional or unintentional damage.

- Cloud modification through sea water injection. Low-level maritime stratocumulus clouds could be seeded with seawater aerosol in order to increase their solar reflectivity by enhancing the overall droplet surface area or the longevity of clouds (Latham 1990). Remotely controlled unmanned spray vessels could be used, with limited additional energy requirements (Salter et al. 2008). The implementation of this technology will modify the distributions and magnitudes of ocean currents and regional and local meteorology: temperature, rainfall, wind and land-ocean temperature contrast (Latham et al. 2008). 
- Albedo changes of the earth' surface. Proposals have been made to change the albedo of deserts, cropland, urban areas, and oceans. Floating foils or solids could change the ocean's albedo, but the instability of the sea's surface and the unknown effects on marine ecology make this a rather farfetched option. Because of their size and relatively low asserted ecological and economic value, deserts may be the most attractive type of land cover in this context, even if the albedo change to be gained is relatively minor (Gaskill 2004). In agriculture, new crop varieties may have a higher albedo but similar nutritional value as current varieties (Ridgwell et al. 2009). The albedo of the expanding urban areas can be influenced through lighter roofs and surface pavement, but their combined surface area remains relatively small and hence their cooling effect is one order of magnitude smaller than the potential cooling effect of the deserts and crops (Lenton and Vaughan 2009).

Once deployed, the effectiveness of these SRM options might be large, because their effect on the global radiative balance is almost instantaneous (Lenton and Vaughan 2009). However, the regional climate implications are not yet understood and could be adverse. In addition, most of the options are still in a very conceptual phase, and some decades will be needed to further research their feasibility, costs and risks. The feasibility of the option varies. Technologically, probably many of the expected hurdles can be overcome. Economically, some of the options, such as space reflectors, are currently estimated to be prohibitively expensive, while other options (stratospheric aerosols, sea water injection) are claimed to be very cheap (e.g., see Barrett 2008; Bickel and Lane 2009; Bles 2009). The full accounting of the environmental risks may challenge such findings, however. For example, model calculations have suggested that precipitation patterns may change as a result of solar radiation management (Matthews and Caldeira 2007; Robock et al. 2008). Covering deserts is likely to have negative ecologic affects, not only on desert ecosystems, but also because of effects on the spreading of Sahara dust. Whitening urban areas can reduce the urban heat island effect, but will not be sufficient to counteract warming at a global scale. Main problems are also the continuation of ocean acidification and the need to maintain the system until other measures have brought down global greenhouse gas concentrations, to prevent the unmasking of the warming associated with greenhouse gas concentrations (Robock 2008). Particularly because of the large risks and the possibility of unilateral action, solar radiation management is controversial and has various serious political implications (e.g., Fleming 2007b; Barrett 2008). Some of the ethical and governance questions are discussed later in this paper.

\section{Emergency adaptation}

If climate change would not be slowed down sufficiently by successful implementation of the above categories of options, adaptation to the remaining consequences would be the only solution. A successful implementation of the first three options depends on a very uncertain internationally coordinated effort, triggered by an equally uncertain sense of urgency in a world with multiple crises. Therefore, it would be wise to anticipate relevant adaptation options which may go beyond the options considered today. Some examples:

- Broadening the portfolio of adaptation options. In a situation of 'recognised ignorance', enhancement of adaptive capacity with 'soft' measures, such as insurance and disaster planning, may prevent investments in "hard" measures that later would be deemed 
unnecessary. Also, adaptation options that are more radical than the currently considered incremental options, may be required and deserve further exploration. Examples include evacuation of vulnerable areas, new agricultural practices, floating cities, and development of new fresh water sources.

- Flexibility and anticipation. Another option is anticipating design, at little extra cost, taking into account the possibility that, at a later stage, constructions may have to be enlarged or changed to respond to the impacts of an accelerating climate change, at the same time minimising the risk that investments already made, may prove to have been unnecessary.

- Integrating climate into non-climate foreign policies. Most countries currently frame adaptation in the context of vulnerability to climate impacts within their borders. However, the economies of many countries may be more vulnerable to the indirect effects of climate change impacts elsewhere, e.g., through changing prices of agricultural products or energy. How these possibilities could be taken into account in economic, trade, energy and agricultural policies, has not yet been systematically analysed.

- Avoiding or managing refugees. While climate change is likely to continue to be just one of many reasons for people to flee their homes, it is projected to become a factor of increasing importance (e.g., EACH-FOR 2008; Kollmanskog 2008). Increasing the adaptive capacity of the most vulnerable regions would reduce the number of climate refugees, but controlled migration may also be seen as an active adaptation option, rather than a sign of failing adaptation (Guillaume 2009).

- Avoiding or managing security implications of rapid climate change. In a changing climate, nations may move from negotiation and collaboration to the pursuance of narrow self-interest with all political and maybe even military means at their disposal. In such a situation increased tensions related to resource scarcity and associated increased commodity prices are likely (e.g., CNA 2007). Security issues can be related to energy, food and water security. Both nationally (e.g., by the US military) and internationally (NATO, Security Council) climate change has already been recognized as a security issue.

- Preventing impacts. Proposals also have been made to prevent particular impacts after the climate has changed. For example, ocean acidification may be addressed by liming the ocean, the strengths of hurricanes and other storms might be reduced by seeding clouds, and even a fully artificial environment may protect mankind from an inhospitable outside climate can be imagined. So far, weather modification attempts in countries, such as the United States (see e.g. Fleming 2007b) and China were all unsuccessful.

The effectiveness of the above adaptation measures depends on the magnitude of the remaining impacts, and it is important to note that there are limits to adaptation, e.g. some impacts may be irreversible. Economic costs and societal ability to adapt will determine the feasibility of the above options - there are also social limits to adaptation, determined by definitions and goals of adaptation and cultural barriers (Adger et al. 2009). The environmental risks of the adaptation options would be overwhelmed by the impacts of extreme climate change. The political implications of allowing the climate to change so fast that emergency measures are required are huge. Much of the changes are likely to manifest themselves via increased magnitudes and frequency of extreme events, and increased societal, economic and military tensions are likely to ensue. The current well-organized climate negotiations may be replaced by much more short-term power politics. Many of the emergency options described above would involve serious ethical and governance questions, which are discussed further below. 


\section{Trade-offs and time delays}

Within each category the variety of different options is large and involves a complex balance of positive and negative aspects. Therefore, no clear winning or losing options can be derived from the assessment for a situation of rapid climate change. The Royal Society (2009) made an attempt to synthesize the various options in one figure, but since there are many more than two dimensions to consider in the evaluation and in emergency situations, perceptions of what is acceptable or not can change fast, such synthesis necessarily provides partial and maybe misleading information. For example, in an emergency situation options that are now considered to be too controversial in many places, such as nuclear energy and behavioral or economic structural changes, may become acceptable. The eventual mix of options will not depend on current preferences and technologies, but on evolving real-world circumstances (e.g. international co-operation) and ultimate policy objectives. For example, if attempts to cut greenhouse gas emissions would appear not to be effective in a timely manner, and at the same time there is political agreement that impacts are to be prevented, options with asserted rapid effects and relatively low, direct economic costs, such as some solar radiation management options, may become attractive - at least as options to buy time to eventually bring down greenhouse gas emissions and concentrations (e.g., see Fig. 2). Alternatively, if geo-engineering options are deemed unacceptable because of associated risks, adaptation to more extreme climatic change impacts could be unavoidable.

The factor time plays a key role in this debate. First, because of the interdecadal variability of the climate system, even targeted monitoring programs may only gradually reveal that climate change would indeed be accelerating. Therefore, it is possible that an accelerating climate change will reveal itself only through a gradually increasing series of observed changes and events that cannot be fully or partly attributed to climatic change,

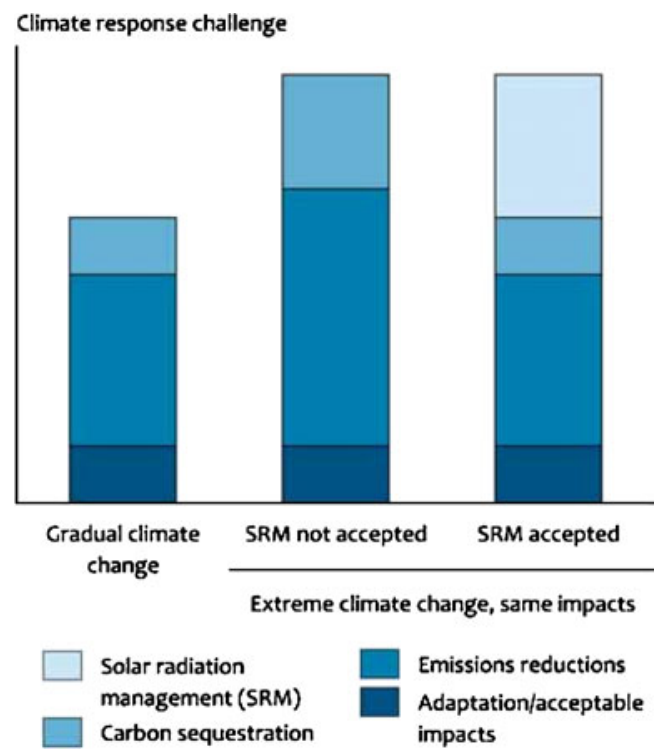

Fig. 2 Trade-off between options in case of more rapid climate change: without additional emissions reductions or carbon sequestration, solar radiation management would be required to limit impacts to the same level as in case of slower climate change 
although abrupt climate change equivalents of 'the hole in the ozone layer' cannot be excluded. This implies, that not everyone would be convinced at the same time. Furthermore, the various options have very different temporal characteristics. Some of the emissions reduction and sink enhancement options are well known today, but speeding them up will require time, and the eventual climate effect will be delayed by inertia in the climate system. Other options, like solar radiation management do not have such system delays, but developing, testing and deploying the technology as well as reaching international consensus about it would also take time. Therefore, we conclude that none of the options is likely to lead to the desirable effect within at least two decades.

\section{Ethical questions}

Climate change involves a large number of ethical questions. Mostly, the scientific debate focuses on issues relating to the question of responsibility, fair allocation of emission rights and costs, access to technologies, or procedural equity. All categories of options involve ethical questions, but because of its particularly controversial character, this is especially true for solar radiation management options, many of which pose a 'moral hazard'. Brown et al. (2006) distinguish four ethical issues, related to aerosol injection into the stratosphere, which are also relevant for other types of solar radiation management:

- The difference between inadvertent and intentional interference with the climate system. Different from the collective development of a world economy based on fossil energy with initially no knowledge about the climate effects, SRM involves intentional modification of the world climate, which would require attention in new or existing international treaties. Especially the interest of the military (Fleming 2007b) is an important consideration here.

- Scientific uncertainties related to the deployment of these technologies. SRM involves uncertainties with respect to the sensitivity of the climate system to the actions, the effects on the atmospheric composition, possible irreversibility, and the remaining impacts of $\mathrm{CO}_{2}$ concentrations. Ethical questions relate to the burden of proof (attribution of responsibility, level of proof required), the rights of protection or compensation of possible victims, and the appropriate use of the precautionary principle.

- The issue that one or a small group of countries (or companies) can determine the 'optimal' climate for the planet. What are the rights of those implementing the options, absent any democratically empowered institution? At present, there do not seem to be any countries - or other actors - that have a clear motivation to act unilaterally. However, in an emergency situation, multilateral institutions, such as UN bodies characterized by slow consensus building and unanimity rule, may be overruled by a 'coalition of the willing'.

- The need for or desirability of further research. Usually, SRM researchers acknowledge the various questions regarding associated risks, and call for more research to address the uncertainties (e.g., Blackstock et al. 2009). However, the mere decision to do research or not involves ethical questions. Such a decision may lead to less efforts to reduce emissions, to lower mitigation research budgets, or deployment or tests without international consent.

It is important to note that the validity of these points varies between different types of options. The ethical challenges are the most serious for options that have potential longlasting, maybe irreversible, large-scale effects, and can be deployed by one or a small group 
of countries. Some of the carbon dioxide removal options have much less serious risks. So far, much of the debate is about "geoengineering" as if this would be one option. It appears to be time to start a more serious debate which takes into account the variety and the very different characteristics of the options.

\section{Disparate perspectives on controversial solutions}

Inherent to such ethical issues, different people have different views. Participating in various national and international discussions about geo-engineering, we observed three ways of framing the problem. Theses frames emerged most clearly in discussions about what is arguably the most controversial option, solar radiation management (Table 1). Proponents of solar radiation management as a technological fix may see this option as a solution that can at least partially counteract the radiative forcing of greenhouse gases, for example, by allowing for higher levels of stabilised concentrations than would be desirable without them. Such a view would decrease the urgency and importance of greenhouse gas emission reductions. For these "climate engineers", solar radiation management may be comparable with fire fighting: in an emergency situation one doesn't care about the collateral water damage. On the other side of the spectrum are those who do not agree with any form of geoengineering, including research, because of the risks involved. This perspective is strongly represented in environmental NGOs, which are usually in favour of what we have called drastic emission reductions, seeing proponents of solar radiation management as the sorcerer's apprentices, unable to control the consequences of their actions. In between are those who see solar radiation management as a potential temporary emergency measure that may not be desirable, but perhaps unavoidable if major climate impacts are to be prevented. In the latter case, the options are to be maintained until greenhouse gas concentrations have been reduced through measures with less risks involved, but with longer lead times. For this group, well represented in some government bureaucracies, solar radiation management could be compared with a physician's job: apply medicine for short-term treatment at the same time as addressing the longer-term problem of the underlying causes. While the emphasis in the currently emerging debate on emergency response measures is on geoengineering, also the other options raise ethical questions. For drastic emissions reduction these can relate to matters of personal freedom and choice. For emergency adaptation, fundamental questions relate to issues such as the fate of particularly vulnerable nations, and liability and compensation for those suffering damages (Brown et al. 2006).

\section{Governance of emergency climate measures}

In an emergency situation, existing governance structures will be put to the test. Different actors will have different views on how to prioritize and organize the responses. Ideally, preparation for addressing the possibility of extreme climatic changes and the management of emergency response options, if and when needed, would be organized in an internationally coordinated, orderly way. For the moment ignoring the possibility that this may not happen, we can envisage various ways to deal with such situations. In the first place, existing multinational institutional mechanisms could be used. For example, a protocol in the context of the UNFCCC on solar radiation management or other emergency response options could be envisaged. Alternatively, more specialized United Nation (UN) 


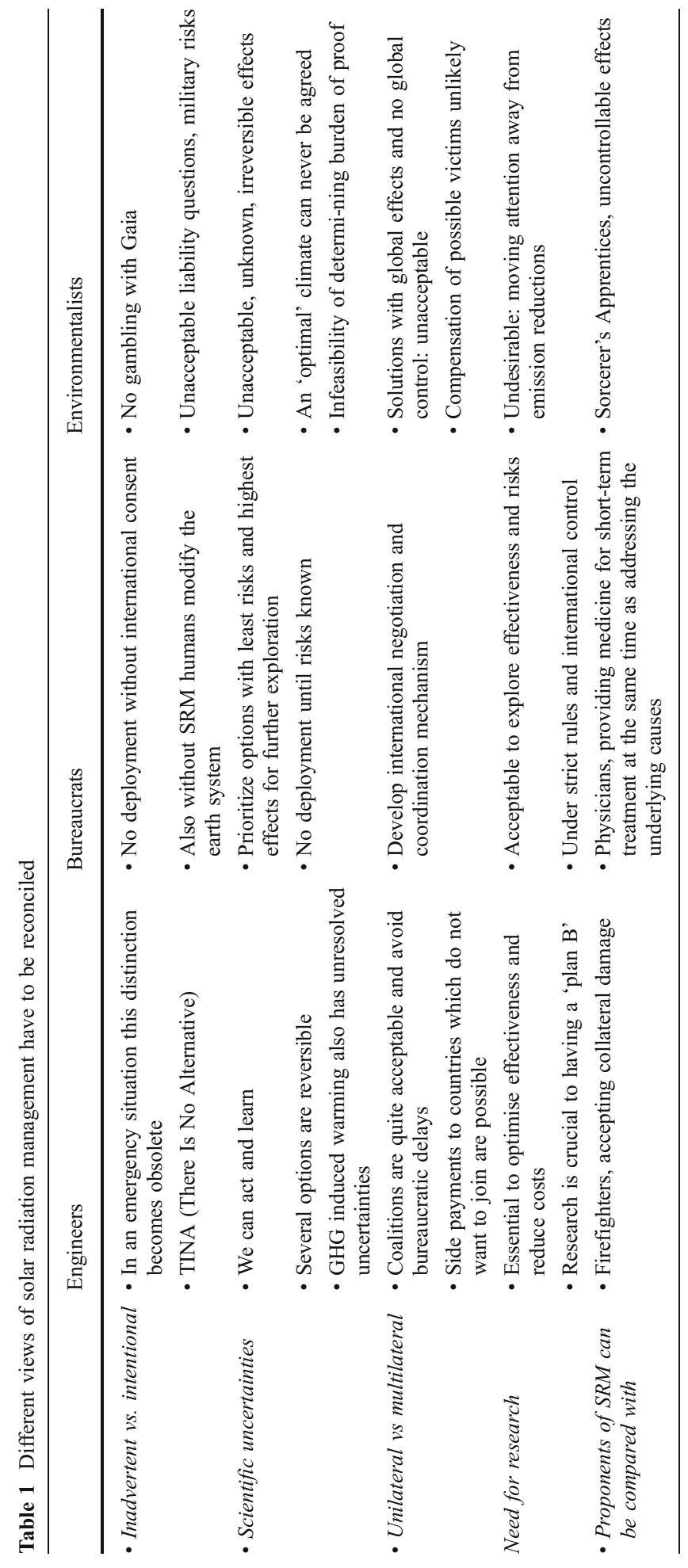


mechanisms could consider the implications of extreme climate change and specific response options, for example, ocean fertilization has been addressed already by the London Convention of the Law of the Sea and the Convention on Biological Diversity. For space reflectors, the Outer Space Treaty (in full: "Treaty on Principles Governing the Activities of States in the Exploration and Use of Outer Space, including the Moon and Other Celestial Bodies") could be considered, and for other SRM options the Convention on Environmental Modification (ENMOD) can be relevant, almost forgotten agreements from the 70s which target primarily military operations. The Convention on Long-Range Transboundary Air Pollution (CLRTAP) and the Vienna Convention on the Protection of the Ozone Layer are important when it comes to sulfur aerosol injections into the stratosphere. Various mechanisms for refugee protection and management, like the UN High Commissioner for refugees (UNHCR) can address the issue of "climate refugees". The International Council of Scientific Unions (ICSU) or the Earth System Science Partnership (ESSS) may assist in developing international rules for research on controversial response options. During the recent Asilomar International Conference On Climate Intervention and Geoengineering Technologies, first steps were taken towards identifying potential risks and propose voluntary standards for climate intervention research (Kintish 2010; Tollefson 2010).

But these multilateral mechanisms may be inadequate or not suitable for the situation of accelerating climate change, and new mechanisms may be required. The IPCC should include governance aspects in the planned extended review of geoengineering in its next assessment report. Since air pollution has grown from a continental to a global problem, the current CLRTAP may not be adequate anymore and may grow into or be replaced by a Global Atmosphere Convention that could also address some of the issues discussed above. But also new institutions or new coalitions outside the UN system or mandated by the UN system may be more effective in dealing with the challenges of an emergency climate response than current multilateral institutions which focus on consensus-building, unanimous decisions and gradual change. However, new institutions with simpler decision-making structures may raise questions as to the level of democratic control. An interesting example that could provide ideas is the Agreement on an International Energy Program (IEP, see IEA 2008) to address oil crises in an internationally coordinated fashion, even if the nature of the climate problem surpasses the characteristics of usually more shortlived oil crises. The IEP not only calls for 60 days emergency oil reserves, but also requires participating countries to have plans for contingent oil demand restraint, evaluated by a Standing Group on Emergency Questions which reports to a Governing Board which decides on a majority basis.

\section{Conclusions}

In summary, we think that the recent accumulation of evidence that the climate may change faster and impacts may be graver than assessed until recently warrants some new steps to be taken by policy makers and science managers. Since uncertainties are large and possible climate eventualities still speculative, such steps could be taken in parallel to the ongoing policy negotiations and supporting scientific assessments, not to interfere with those negotiations at this time.

If and when signs of rapid climate change are identified and are considered to be a sufficient basis for action, policy makers will have to decide on a mix of "emergency" measures. It is now time to take a step beyond the general and often emotional discussions 
about emergency response options such as geoengineering and structural changes in consumption and production practices. We propose to start a broad discourse in which the full diversity of options is taken into account to ensure that responsible decisions-if and when they would be needed - would be made on the basis of sound information rather that on the basis of the lowest short-term economic and political costs. If through concerted international efforts to mitigate greenhouse emissions low stabilization levels could be reached, such decisions may never have to be made. However, a cautious start with a political, rational and non-alarmist debate on a "plan B" may be warranted, focusing on those options that have the most positive ratio between potential effectiveness and feasibility on the one hand, and environmental and political risks on the other hand. These options should go beyond the "climate intervention and geoengineering technologies" discussed during the recent Asilomar conference, and explicitly take into account not only the relationships between the full portfolio of options including drastic mitigation and adaptation measures, but also the wide variety in characteristics of the individual options in each category in terms of effectiveness, feasibility, environmental risks, and political implications.

Such a plan B should be supported by the results of new research on rapid climate change and innovative emergency response options. In order to address the many knowledge gaps, two priority research strategies can be pursued: (a) improved monitoring of rates of climate change and potential tipping points and (b) research into all relevant characteristics of the full portfolio of emergency response options. A key problem is that a possible signal of climate change may be masked by climate variability for some time. Current monitoring and early warning systems may not be optimally designed for the purpose to identify threshold behaviour in parts of the climate system. Targeted monitoring of tipping points may warrant an upgrading or even major revision of the current monitoring systems. Emergency response research would go beyond the analysis of important but incremental improvements of the current set of adaptation and mitigation options. It would include the environmental, technical and socio-economic assessment of innovative and possibly controversial response options, including geoengineering and transitions in consumption and production patterns.

Open Access This article is distributed under the terms of the Creative Commons Attribution Noncommercial License which permits any noncommercial use, distribution, and reproduction in any medium, provided the original author(s) and source are credited.

\section{References}

Angel R (2006) Feasibility of cooling the Earth with a cloud of small spacecraft near the inner Lagrange point (L1). Proc Natl Acad Sci USA 103:184-189

Adger WN, Dessai S, Goulden M, Hulme M, Lorenzoni I, Nelson D, Naess O-N, Wolf J, Wreford A (2009) Are there social limits to adaptation to climate change? Clim Change 93:335-354

Austin A (2009) Biomass '09: Transgenic algae pose environmental risks. Biomass magazine http://www. biomassmagazine.com/article.jsp?article id=2873, cited 30 Dec 2009

Bala G, Duffy PB, Taylor KE (2008) Impact of geoengineering schemes on the global hydrological cycle. Proc Natl Acad Sci USA 105:7664-7669

Barrett S (2008) The incredible economics of geoengineering. Environ Res Econ 39:45-54

Bickel JE, Lane L (2009) An analysis of climate engineering as a response to climate change. Björn Lomborg's Copenhagen Consensus on Climate,. Available via AEI http://www.aei.org/article/100863. Cited 15 Dec 2009 
Blackstock JJ, Battisti DS, Caldeira K, Eardley DM, Katz JI, Keith DW, Patrinos AAN, Schrag DP, Socolow RH, Koonin SE (2009) Climate engineering responses to climate emergencies. Available via Novim http://www.novim.org/. Cited 15 Dec 2009

Bles M (2009) Climate response plan B: an assessment of geoengineering techniques. Research project report CE Delft

Boyd PW (2008) Ranking geoengineering schemes. Nature Geosci 1:722-724

Brown D, Tuana N, et al (2006) White paper on the ethical dimensions of climate change. Available via Program on the Ethical Dimensions of Climate Change, Rocks Ethics institute, Pennsylvania State University http:// www.psu.edu/dept/rockethics/climate/whitepaper/edcc-whitepaper.pdf. Cited 15 Dec 2009

Budyko MI (1969) The effect of solar radiation variations on the climate of the Earth. Tellus 21:611-619

California Energy Commission (2008) 2008 building energy efficiency standards. CEC

CCSP (2008) Abrupt climate change. A report by the U.S. Climate Change Science Program and the Subcommittee on Global Change Research. Clark PU and Weaver AJ (coordinating lead authors), Brook E, Cook ER, Delworth TL and Steffen K (chapter lead authors). U.S. Geological Survey, Reston, VA, pp 459

CNA (Centre for Naval Analysis) (2007) National Security and the Threat of Climate Change http:// securityandclimate.cna.org/report/National $\% 20$ Security $\% 20$ and $\% 20$ the $\% 20$ Threat $\% 20$ of $\% 20$ Climate $\%$ 20Change.pdf, cited 15 March 2010

Crutzen P (2006) Albedo enhancement by stratospheric sulfur injections: a contribution to resolve a policy dilemma? Clim Change 77:211-219

EACH-FOR (2008) Preliminary findings from the EACH-FOR project on environmentally induced migration. The European Research Centre on Migration and Ethnic Relations, Erasmus University Rotterdam (EUR/Erasmus MC), The Netherlands

EpE/Iddri (2008) Scenarios for transition towards a low-carbon world in 2050: what's at stake for heavy industries? EpE/IDDRI, France

Early JT (1989) Space-based Solar Shield to Offset Greenhouse Effect. J of the British Interplanetary Society 42:567-569

Fleming D (2007a) Energy and the common purpose. Descending the Energy Staircase with Tradable Energy Quotas (TEQs). Available via The Lean Economy Connection http://www.theleaneconomyconnection. net/downloads.html. Cited 15 Dec 2009

Fleming J (2007b) The climate engineers, Wilson Quarterly

Füssel H-M (2009) An updated assessment of the risks from climate change based on research published since the IPCC Fourth Assessment Report. Clim Change 97:469-482

Gaskill A (2004) Summary of meeting with U.S. DOE to discuss geoengineering options to prevent abrupt and long-term climate change. http://www.global-warming-geo-engineering.org/DOE-Meeting/DOEGeoengineering-Climate-Change-Meeting/ag1.html. Cited 15 Dec 2009

Green New Deal Group (2008) A green new deal. New Economics Foundation

Grobelaar J, Mmohn F, Soeder C (2000) Potential of algal mass cultures to fix CO2 emissions from industrial point sources. Archiv für Hydrobiologie, Supplementband Algological studies 133:169-183

Guillaume B (2009) Avoiding a 4oC world: a challenge for democracy. Presentation at 4 Degrees and Beyond International Climate Conference, Oxford University, Oxford, UK, 28-30 September 2009

Hillman M, Fawcett T (2004) How we can save the planet, Penguin Putnam

IEA (2008) Agreement on an International Energy Program, Available via International Energy Agency, Paris http://www.iea.org/about/docs/IEP.PDF. Cited 15 Dec 2009

IPCC (2007a) Climate Change 2007: Mitigation. Contribution of Working Group III to the Fourth Assessment Report of the Intergovernmental Panel on Climate Change. Metz B, Davidson OR, Bosch PR, Dave R and Meyer LA (eds), Cambridge University Press, Cambridge, United Kingdom and New York, NY, USA

IPCC (2007b) Contribution of Working Group I to the Fourth Assessment Report of the Intergovernmental Panel on Climate Change, Solomon S, Qin D, Manning M, Chen Z, Marquis M, Averyt KB, Tignor Mand Miller HL (eds.), Cambridge University Press, Cambridge, United Kingdom and New York, NY, USA

Janssen MJ, Tramper L, Wijffels R (2003) Enclosed outdoor photobioreactors: light regime, photosynthetic efficiency, scale-up, and future prospects. Biotechnol Bioeng 81:193-210

Kattenberg A, Verver G (2009) Exploring the boundaries of climate change. A review of thirteen climate eventualities. KNMI, De Bilt

Keith D, Ha-Duong M, Stolaroff JJ (2005) Climate strategy with CO2 capture from the air. Clim Change 74:17-45 Kheshgi HS (1995) Sequestering atmospheric carbon dioxide by increasing ocean alkalinity. Energy 20:915-922

Kintish E (2010) 'Asilomar 2' takes small steps toward rules for geoengineering. Science 328:22-23

Kollmanskog VO (2008) Future floods of refugees. A comment on climate change, conflict and forced migration. Available via Norwegian Research Council, Oslo http:/www.nrc.no/arch/_img/9268480.pdf. Cited 15 Dec 2009 
Kriegler E, Hall JW, Held H, Dawson R, Schellnhuber H-J (2009) Imprecise probability assessment of tipping points in the earth system. Proc Natl Acad Sci USA 106:5041-5046

Lackner KS (2009) Capture of carbon dioxide from ambient air. Eur Phys J-Special Topics 176:93-106

Lackner KS, Grimes P, Ziock H-J (2001) Capturing carbon dioxide from air. In: First National Conference on Carbon Sequestration, National Energy Technology Laboratory, Washington, DC

Lampitt RS, Achterberg EP, Anderson TR, Hughes JA, Iglesias-Rodriguez MD, Kelly-Gerreyn BA, Lucas M, Popove EE, Sanders R, Shepherd JG, Smythe-Wright D, Yool A (2008) Ocean fertilization: a potential means of geoengineering? Philos Trans R Soc A 366:3919-3945

Latham J (1990) Control of global warming. Nature 347:339-340

Latham J, Rasch PJ, Chen CC, Kettles L, Gadian A, Gettelman A, Morrison H, Salter S (2008) Global temperature stabilization via controlled Albedo enhancement of low level maritime clouds. Philos Trans R Soc A 366:3969-3987

Lehmann J (2007) Bio-energy in the black. Front Ecol Environ 5:381-387

Lehmann J, Gaunt J, Rondon M (2006) Bio-char sequestration in terrestrial ecosystems - a review. Mitig Adapt Strateg Glob Change 11:403-427

Lenton and Vaughan N (2009) The radiative forcing potential of different climate geo-engineering options. Atmos Chem Phys Discuss 9:1-50

Lenton T, Held H, Kriegler E, Hall JW, Dawson R, Schellnhuber H-J (2008) Tipping element's in the earth's climate system. Proc Natl Acad Sci USA 105:1786-1793

Matthews HD and Caldeira K (2007) Transient Climate-carbon Simulations of Planetary Geoengineering, Proc Natl Acad Sci USA 104:9949-9954

McKinsey (2009) Pathways to a low-carbon economy: version 2 of the Global Greenhouse Gas Abatement Curve. Available via McKinsey https://solutions.mckinsey.com/ClimateDesk/default.aspx. Cited 15 Dec 2009

Michaelson J (1998) Geoengineering: a climate change Manhattan project. Available via Stanford Environ Law J http://www.metatronics.net/lit/geo2.html. Cited 15 Dec 2009

Nabuurs et al (2007) Forestry. in Climate Change 2007: Mitigation. Contribution of Working Group III to the Fourth Assessment Report of the Intergovernmental Panel on Climate Change. Metz B, Davidson OR, Bosch PR, Dave R and Meyer LA (eds), Cambridge University Press, Cambridge, United Kingdom and New York, NY, USA

NAS (1992) Policy Implications of Greenhouse Warming: Mitigation, adaptation and the science base. Panel on Policy Implications of Greenhouse Warming, National Academy Press, 918pp

NASA (2009) NASA Envisions "Clean Energy" From Algae Grown in Waste Water http://www.nasa.gov/ centers/ames/news/features/2009/clean nergy 042209.html, cited 30 Dec 2009

Nikulshina V, Galvez ME, Steinfeld A (2007) Kinetic analysis of the carbonation reactions for the capture of $\mathrm{CO} 2$ from air via the $\mathrm{Ca}(\mathrm{OH}) 2-\mathrm{CaCO} 3-\mathrm{CaO}$ solar thermochemical cycle. Chem Eng J 129:75-83

Ornstein L, Aleinov I, Rind D (2009) Irrigated afforestation of the Sahara and Australian Outback to end global warming. Clim Change 97:409-437

Pidgeon N F, Henwood KL, Parkhill KA, Venables D and Simmons P (2008) Living with Nuclear Power in Britain: A Mixed Methods Study. School of Psychology, Cardiff University

Rau GH, Knauss KG, Langer WH, Caldeira K (2007) Reducing energy-related CO2 emissions using accelerated weathering of limestone. Energy 32:1471-1477

Richardson C et al (2009) Synthesis Report. Climate Change Congress on Global Risks, Challenges and Decisions. Copenhagen University, Copenhagen, Denmark

Ridgwell AJ, Singarayer AH, Valdes P (2009) Tackling regional climate change by Leaf Albedo Biogeoengineering. Curr Biol 19:146-150

Robock A (2008) Whither geoengineering? Science 32:1166-1167

Robock A, Oman L and Stenchikov G (2008) Regional climate responses to geoengineering with tropical and Arctic SO2 injections. J Geophys Res 113, D16101

Rogeij J, Nabel J, Chen C, Hare W, Markmann K, Meinshausen M, Schaeffer M, Macey K, Höhne N (2010) Copenhagen Accord pledges are paltry. Nature 464:1126-1128

Royal Society (2009) Geoengineering the climate: sciencde, governance and uncertainty. RS Policy document 10/09, The Royal Society, United Kingdom

Salter S, Sortino G, Latham J (2008) Sea-going hardware for the cloud Albedo method of reversing global warming. Philos Trans R Soc A 366:3989-4006

Schneider S (2008) Geoengineering: could we or should we make it work? Philos Trans R Soc London A 366:3843-3862

Seifritz W (1989) Mirrors to halt global warming? Nature 340: 603

Sijtsma L, Reith H (2006) Duurzame productie en ontwikkeling van biomassa,zowel in Nederland als in het buitenland. SenterNovem, Platform Groene Grondstoffen 
Smith J et al (2009) Assessing dangerous climate change through an update of the Intergovernmental Panel on Climate Change (IPCC) 'reasons for concern'. Proc Natl Acad Sci USA 106:4133-4137

Steffen W (2009) Climate change 2009: faster change and more serious risks available via Australian Government, Dep of Clim Change. http://www.climatechange.gov.au/ /media/publications/science/cc-faster_change.ashx. Cited 15 Dec 2009

Stephens JC and Keith DW (2008) Assessing Geochemical Carbon Management. Climatic Change 90:217242

Swart R, Marinova N, Bakker S, van Tilburg X (2009) Policy options to respond to rapid climate change. Alterra Report 1950, Alterra Wageningen University and Research Centre

Tollefson J (2010) Geoengineers get the fear. Nature 464:656

UNEP (2009) Climate change 2009: Science Compendium. Available via UNEP, Nairobi http://www.unep. org/compendium2009/. Cited 15 Dec 2009

van Minnen JG, Strengers BJ, Eickhout B, Swart RJ and Leemans R (2008) Quantifying the effectiveness of climate change mitigation through forest plantations and carbon sequestration with an integrated landuse model. Carbon Balance and Management 3:3

Van Vuuren D, Stehfest E (2009) Exploring the effectiveness of emergency responses to climate change. In: Swart R, Marinova N, Bakker S, van Tilburg X (2009) Policy options to respond to rapid climate change. Alterra Report 1950, Alterra Wageningen University and Research Centre

WBGU (2009) Solving the climate dilemma: the budget approach. Available via German Advisory Council on Global Change, Berlin http://www.wbgu.de/wbgu_sn2009_en.pdf). Cited 15 Dec 2009.

Wilson JC, Jonsson HH, Brock CA, Toohey DW, Avalone LM, Baumgardner D, Dye J, Poole LR, Woods DC, DeCoursey RJ, Osborne M, Pitts MC, Kelly KK, Chan KR, Ferry GV, Loewenstein M, Podolske JR, Weaver S (1993) In-situ observations of aerosol and chlorine monoxide after the 1991 eruption of Mount Pinatubo: Effect of reactions on sulfate aerosol. Science 261:1140-1143

Woolf D (2008) Biochar as a soil amendment: a review of the environmental implications. http://orgprints. org/13268/01/Biochar_as_a_soil_amendment__a review.pdf. Cited 15 Dec 2009

Yang C-J, Oppenheimer M (2007) A "Manhattan project" for climate change? Clim Change 80:199-204 